\title{
Effect of Ag on textured electrical ceramics
}

\author{
A. Sotelo ${ }^{1}$, M. A. Torres ${ }^{2}$, Sh. Rasekh ${ }^{1}$, L. C. Estepa ${ }^{1}$, M. A. Madre ${ }^{1}$, J. C. Diez ${ }^{1}$ \\ ${ }^{1}$ ICMA (CSIC-Universidad de Zaragoza), Dpto. de Ciencia de Materiales, \\ C/María de Luna 3, 50018-Zaragoza (Spain). \\ ${ }^{2}$ Universidad de Zaragoza, Dpto. de Ingeniería de Diseño y Fabricación, \\ C/María de Luna 3, 50018-Zaragoza (Spain).
}

\section{INTRODUCTION}

From the discovery of the first ceramic superconductor [1] and thermoelectric oxides with attractive performances [2], much work has been performed on these materials, leading to the discovery of new families, such as the superconducting $\mathrm{Bi}_{2} \mathrm{Sr}_{2} \mathrm{CaCu}_{2} \mathrm{O}_{x}$ [3] or the thermoelectric $\mathrm{Bi}_{2} \mathrm{Sr}_{2} \mathrm{Co}_{1.8} \mathrm{O}_{y}$ [4]. These materials are mainly characterised by their good electrical properties in the conducting planes: $\mathrm{Cu}-\mathrm{O}$ planes in the superconducting and $\mathrm{Co}-\mathrm{O}$ planes in the thermoelectric ceramics, which are coincident with the crystallographic abplanes in both cases. This feature can be exploited in the development of commercial applications for these ceramics, with improved electrical properties, when an adequate grain orientation is produced using texturing techniques. $\mathrm{Bi}_{2} \mathrm{Sr}_{2} \mathrm{CaCu}_{2} \mathrm{O}_{\mathrm{x}}$ (Bi-2212) superconductor and $\mathrm{Bi}_{2} \mathrm{Sr}_{2} \mathrm{Co}_{1.8} \mathrm{O}_{\mathrm{y}}$ (BSCO) thermoelectric materials have demonstrated that they are suitable for many practical applications when they are properly processed in order to produce well oriented grains [5,6]. Among many techniques used successfully to produce 
well textured materials [7-11], the directional growth from the melt by the Laser Floating Zone (LFZ) method has demonstrated to be a very useful technique for producing well textured $\mathrm{Bi}-2212$ and BSCO rods at high growth rates [12-14]. The materials textured by this technique, have very well aligned crystals, with their c-axis perpendicular to the current flow direction, with low angle tilt grain boundaries, obtaining a good electrical connectivity between grains. Moreover, they show very interesting properties, quantified by the critical current density $\left(\mathrm{J}_{\mathrm{c}}\right)$ in the case of $\mathrm{Bi}-2212$ and the thermoelectric power factor (PF) for the BSCO materials, that allow developing practical applications.

One of the main advantages of the LFZ method is that the materials can be rapidly grown due to the large thermal gradient at the solid-liquid interface [15]. A second additional advantage is the absence of crucible, avoiding external contamination.

However, the poor mechanical characteristics of this kind of materials [16], due to their ceramic nature, impose limitations for practical applications. Some attempts to improve the mechanical properties of $\mathrm{Bi}-2212$ have been performed by Ag addition [17] while no studies have been published, to our knowledge, for the mechanical improvement of BSCO.

The aim of this work is to study the effect of $\mathrm{Ag}$ addition on the Bi-2212 and BSCO systems processed by LFZ. The changes produced on the microstructure have been related with the measured electrical and mechanical properties of both families.

\section{EXPERIMENTAL}


Bi-2212/x wt.\%Ag and BSCO/x wt.\%Ag $(x=1,3,5$ and 10) precursors have been prepared from commercial $\mathrm{Bi}_{2} \mathrm{O}_{3}$ (Panreac, $98+\%$ ), $\mathrm{SrCO}_{3}$ (Panreac, 98 $+\%), \mathrm{CaCO}_{3}($ Panreac, $98.5+\%), \mathrm{CuO}($ Panreac, $98+\%), \mathrm{Co}\left(\mathrm{NO}_{3}\right)_{2} \cdot 6 \mathrm{H}_{2} \mathrm{O}$ (Aldrich, $\geq 99 \%$ ) and Ag (Aldrich, $99.9+\%$ ) powders by a sol-gel method via nitrates [18] to assure total cation solution, small particle size and good homogeneity in the initial mixture. The initial powders were suspended in distilled water, followed by dropwise addition of $\mathrm{HNO}_{3}$ (Panreac, analysis grade) until a clear blue (for Bi-2212) or pink (for BSCO) solution was obtained. Citric acid (Panreac, $99.5 \%$ ) and ethylene glycol (Panreac, $99 \%$ ) were added to this solution in the adequate proportions. Evaporation of the solvent was performed slowly in order to decompose the nitric acid excess, which allows the polymerization reaction between ethylene glycol and citric acid, forming a light blue (for the Bi-2212) or light pink (for the BSCO) gel. The dried product was then decomposed (producing a slow self-combustion) by heating at $650 \mathrm{~K}$ for 1 h. The decomposed solid was mechanically ground and calcined at 1025 and $1075 \mathrm{~K}$ for $12 \mathrm{~h}$, with an intermediate grinding. This calcination process has been fixed in previous studies [19] to specifically decompose the alcaline earth carbonates avoiding their decomposition in the LFZ process, which would lead to bubble formation inside the melt, disturbing the crystallization front. From these powders, green cylindrical ceramic precursors were prepared by isostatic pressing at about $200 \mathrm{MPa}$ for 1 minute.

The obtained cylinders were then used as feed in a directional solidification process performed in an LFZ installation [20]. The textured bars were obtained using a continuous power Nd:YAG laser $(\lambda=1064 \mathrm{~nm})$, under air, at a growth rate of $30 \mathrm{~mm} / \mathrm{h}$ and a relative rotation of $18 \mathrm{rpm}$ between seed and feed. Using 
these growth conditions and adjusting the laser power input to obtain a molten zone of 1-1.5 times the rod diameter, it is possible to obtain a stable solidification front, which allows the fabrication of homogeneous textured bars. After the texturing process, some differences are arising between the two types of ceramics:

(i) Bi-2212 ceramics present incongruent melting and, in consequence, after the directional solidification process, it is necessary to perform a thermal treatment in order to form the Bi-2212 superconducting phase [21,22]. This annealing process was performed under air, and consisted in two steps: $60 \mathrm{~h}$ at $1125 \mathrm{~K}$, followed by $12 \mathrm{~h}$ at $1075 \mathrm{~K}$ and, finally, quench in air to room temperature. Before the thermal treatment, silver contacts were painted on the as-grown samples for the electrical measurements. After annealing, the silver contacts have typical resistance values below $1 \mu \Omega$.

(ii) After the directional growth process, thermoelectric ceramics are composed mainly by the thermoelectric phase, together with some secondary phases, with good thermoelectric properties [14,23]. As a consequence, no further treatments are necessary for this type of materials.

Structural identification of all ceramic samples was performed by powder XRD utilizing a Rigaku D/max-B X-ray powder diffractometer (CuKa radiation) with $2 \theta$ ranging between 10 and 60 degrees. Microstructural characterization was performed on polished longitudinal cross-sections of the samples, in a scanning electron microscope (SEM, JEOL JSM 6400) equipped with an energy dispersive spectroscopy (EDX) system. 
Mechanical characterization has been performed by flexural strength, using the three-point bending test in an Instron 5565 machine with a $10 \mathrm{~mm}$ loading span fixture and a punch displacement speed of $30 \mu \mathrm{m} / \mathrm{min}$.

Electrical properties have been determined in different ways for both types of ceramics:

(i) For the Bi-2212/Ag composite materials, annealed samples were, approximately, $4 \mathrm{~cm}$ long and were measured using the standard four-probe configuration. Critical current density $\left(\mathrm{J}_{\mathrm{c}}\right)$ values were determined at $77 \mathrm{~K}$ using the $1 \mu \mathrm{V} / \mathrm{cm}$ criterion. Resistivity as a function of temperature, from 77 to $300 \mathrm{~K}$, was measured using a dc current of $1 \mathrm{~mA}$, in order to determine the transport $\mathrm{T}_{\mathrm{c}}$ values.

(ii) In the case of the BSCO/Ag composites, electrical resistivity $(\rho)$ and thermopower (TEP) were simultaneously determined by the standard dc fourprobe technique in a LSR-3 measurement system (Linseis GMBh). They were measured in the steady state mode at temperatures ranging from approximately 300 to $950 \mathrm{~K}$ under He atmosphere. With the electrical resistivity and thermopower data, the power factor $\left(P F=[T E P]^{2} / \rho\right)$ has been calculated in order to determine the samples' performance.

\section{RESULTS AND DISCUSSION}

\subsection{As-grown materials microstructural characterization}

SEM microstructural observations on as-grown materials showed that all the textured rods are multiphasic for each group of samples (Bi-2212/Ag and $\mathrm{BSCO} / \mathrm{Ag}$ ), indicating that in both cases they have an incongruent melting. Moreover, the secondary phases identified in each family are the same, 
independently of $\mathrm{Ag}$ content, indicating that the melt is chemically similar in each family and that Ag produces minor effects on the solidification process. A representative micrograph of each type of material, performed on longitudinal polished sections of the as-grown materials is displayed in Fig. 1. For the Bi2212/3 wt.\%Ag ceramic (Fig. 1a), five different phases can be observed and identified by EDX. The primary solidification phase is the $\mathrm{Bi}$-free $(\mathrm{Ca}, \mathrm{Sr}) \mathrm{CuO}_{2}$ (dark contrast in the Fig. 1a, and marked as \#1). This phase appears well aligned with the rod axis, as expected from the flat solidification interface observed in the growth process [24]. Light grey phase (marked as \#2 in Fig. 1a) shows a composition close to the ideal $\mathrm{Bi}_{2} \mathrm{Sr}_{2} \mathrm{CuO}_{x}(\mathrm{Bi}-2201)$ stoichiometry. This phase's formation is promoted by its fast solidification kinetics from the Bienriched liquid, a process that follows initial nucleation of $(\mathrm{Ca}, \mathrm{Sr}) \mathrm{CuO}_{2}$. Moreover, from the trends observed in Fig. 1a it can be deduced that the grain growth of this Bi-rich phase mainly follows the alignment of the primary solidified phase. Grey phase (marked as \#3 in Fig. 1a) has a composition close to the stoichiometric $\mathrm{Bi}-2212$ with a slightly lower $\mathrm{Ca}$-content, corresponding to $\mathrm{Bi}$ 2212/Bi-2201 intergrowths, usually appearing between Bi-2201 grains. Small black spots (marked as \#4 in Fig. 1a) distributed inside the Bi-rich phase have been identified as $\mathrm{CaO}$ particles. Finally, \#5 in Fig. 1a is indicating Ag particles, which can be also seen as grey contrasts but can be distinguished by their shapes, as they tend to be spherical.

Similar microstructure is found for the BSCO/Ag ceramics, which is shown in Fig. 1b for the BSCO/5 wt.\%Ag samples. In these samples, five main phases, as well as Ag particles (numbered as \#5 in Fig. 1b) are found. In these samples, Ag tends to change its shape from the spherical one found in Bi-2212/Ag rods, 
to a more elliptical one trying to fill the free space between the alternating thermoelectric grains layers. The major phases found are the grey phase (\#6 in Fig. 1b), corresponding to $\mathrm{Bi}_{2} \mathrm{Sr}_{2} \mathrm{Co}_{2} \mathrm{O}_{y}$, and the light grey contrast (\#7 in Fig. 1b), identified as $\mathrm{Bi}_{2} \mathrm{Sr}_{2} \mathrm{CoO}_{y}$, which appear as well aligned alternated layers. Minor phases appear as white contrast (\#8 in Fig 1b) for the Co-free one, black one (\#9 in Fig 1b) for $\mathrm{CoO}$, and dark grey (\#10 in Fig 1b), with a composition close to the thermoelectric $\mathrm{Sr}_{2} \mathrm{Co}_{2.8-\mathrm{x}} \mathrm{Bi}_{x} \mathrm{O}_{\mathrm{y}}$ one [25].

Another important feature arising from SEM observations is that for all samples with 5 wt.\%Ag, big Ag particles are found, as illustrated by Fig. 2 where a representative transversal polished section of $\mathrm{BSCO} / 5 \mathrm{wt} . \% \mathrm{Ag}$ is displayed. From these observations, it is clear that the Ag solubility is very low in both families.

From the above observations, it is clear that $\mathrm{Bi}-2212 / \mathrm{Ag}$ samples must be annealed in order to promote the formation of the superconducting $\mathrm{Bi}-2212$ phase while it is not necessary in the case of the BSCO/Ag composites as in previous works it has been demonstrated that these as-grown materials posses interesting thermoelectric properties [14]. As a consequence, $\mathrm{Bi}-2212 / \mathrm{Ag}$ samples will be studied after annealing while BSCO samples will be characterized in the as-grown state.

\subsection{XRD characterization}

Powder XRD patterns for the different BSCO/Ag composite samples, grown by the LFZ process, are displayed in Fig. 3. From these data, it is clear that all the samples have very similar diffraction patterns and show minor peaks corresponding to non-thermoelectric secondary phases. The highest peaks 
belong to the misfit cobaltite phase and are in agreement with previously reported data [26]. Weak diffraction peaks (marked with a $\boldsymbol{\nabla}$ ) are related with the solid solution Bi-Sr-O secondary phases, the indicates the Si (111) diffraction peak, used as reference, and \# marks the (111) peak of $\mathrm{Ag}$, which is difficult to observe as it is appearing as a shoulder on the $\sim 38.5^{\circ}$ diffraction peak.

For the Bi-2212/Ag materials, the powder XRD plots have been recorded after the annealing process performed at $1125 \mathrm{~K}$ for $60 \mathrm{~h}$ to produce the $\mathrm{Bi}-2212$ phase formation. As it can be clearly seen in Fig. 4, the diffraction patterns are very similar for all the samples, independently of the Ag content, showing that they are composed by nearly pure Bi-2212 phase. Major peaks are associated to the $\mathrm{Bi}-2212$ phase, accompanied by small amounts of $\mathrm{Bi}-2201$ (indicated by * in Fig. 4). On the other hand, $\mathrm{Ag}$ (marked with \#) is only detected for samples with 3 or 5 wt. $\% A g$.

\subsection{Microstructural characterization of annealed Bi-2212/Ag composites}

When observing SEM micrograph presented in Fig. 5 (corresponding to a Bi$2212 / 3$ wt. \%Ag transversal polished section), it is clear that major phase is $\mathrm{Bi}-$ 2212 (grey contrast) as it was found on the XRD analysis. In contrast, there are still some minor secondary phases identified by EDX as Bi-2201 (white contrast), and $(\mathrm{Sr}, \mathrm{Ca}) \mathrm{CuO}_{2}$ (dark grey contrast). Moreover, Ag particles can also be found, with a different shape than they showed in the as grown samples. This shape change of the Ag particles is due to the formation of a liquid phase [27] and its migration to the elongated holes between superconducting grains, originated in the $\mathrm{Bi}-2212$ formation process from $\mathrm{Bi}$ - 
2201 and other secondary phases. The number and size of these silver inclusions increases with $\mathrm{Ag}$ content leading, in the case of the $5 \mathrm{wt} . \% \mathrm{Ag}$ samples, to the formation of big spherical particles (already observed in Fig. 2).

Due to the high stability of these big spherical particles, they do not change their shape in the relatively short annealing time, as it is illustrated with Fig. 6 where an annealed $\mathrm{Bi}-2212 / 5$ wt.\%Ag transversal polished section is presented. In this figure it is possible to see a slight plastic deformation from the spherical shape due to the superconducting grains growth during the thermal treatment. Moreover, these Ag particles induce the misalignment of their superconducting surrounding grains.

\subsection{Mechanical characterization}

To study the mechanical behaviour, flexural strength tests were made on asgrown BSCO/Ag and annealed Bi-2212/Ag samples, using at least six samples for each composition.

In Fig. 7 it is represented the flexural strength values as a function of $\mathrm{Ag}$ content for the as-grown BSCO/Ag samples together with their standard error. At first sight it is clear that the Ag addition improves mechanical properties, compared with the pure samples, in an important manner independently of the Ag amount. Moreover, Ag addition reduces the standard error values in all cases. The best mechanical strength values are obtained for small Ag contents due to the small size and good distribution of Ag particles all over the ceramic matrix, producing an increase of about $25 \%$ from the values obtained for the pure Bi-2212. This effect is produced by the Ag particles found between superconducting platelets which provide a plastic-flow region, reducing crack propagation [17]. The 
progressive decrease of flexural strength for higher Ag contents can be associated to the Ag particles size increase, reducing their ability to adapt their shape to that of the holes between the superconducting grains.

For the Bi-2212/Ag annealed samples, a very similar behaviour is found. As it can be seen in Fig. 8, the best results are obtained for small Ag additions, where an increase of about $40 \%$ has been obtained for samples containing 1 wt.\%Ag. Moreover, as it was observed and explained for higher silver contents, flexural strength decreases significantly.

\subsection{Thermoelectric characterization of as-grown BSCO/Ag composites}

The temperature dependence of the resistivity, as a function of Ag content is shown in Fig. 9. The $\rho(T)$ curves show an important decrease of the resistivity with Ag addition, which must be related to the improved TE grains electrical connectivity, as this behaviour can not be explained using a resistivity-mixture rule [28]. The minimum value at room temperature is around $200 \mu \Omega . m$ for high Ag content ( 3 and 5 wt.\%Ag), about the best reported values for this type of textured materials measured on the ab plane at around $550 \mathrm{~K}$ [29].

Fig. 10 shows the variation of the thermopower with the temperature as a function of Ag content. The sign of the thermopower is positive for the entire measured temperature range, which confirms a mechanism involving a predominant hole conduction mechanism. The values of the thermopower show two different behaviours, one for samples with $\mathrm{Ag}$ contents $\leq 1 \mathrm{wt} . \%$ and the other for higher Ag contents. In the first case, TEP is decreasing from room temperature to around $775 \mathrm{~K}$ and then increases while for high Ag additions, TEP is increasing from room temperature to around $575 \mathrm{~K}$ and decreasing for 
higher temperatures. The maximum value at room temperature is reached for the 5 wt.\%Ag samples (about $150 \mu \mathrm{V} / \mathrm{K}$ ) which is higher than those reported for solid state sintered materials (about $120 \mu \mathrm{V} / \mathrm{K}$ ) or textured ones (about 140 $\mu \mathrm{V} / \mathrm{K})$. The high TEP value obtained for these samples can be explained by the high number of oxygen vacancies generated on the LFZ growth process which are probably produced in larger amounts than in samples synthesized in a classic solid state reaction. As a consequence, in order to maintain the electrical neutrality, a reduction of $\mathrm{Co}^{4+}$ to $\mathrm{Co}^{3+}$ is produced, leading to the decrease of holes concentration [30]. It has already been evidenced that, under reduced conditions, the misfit phase $\left[\mathrm{Ca}_{2} \mathrm{CoO}_{3}\right]\left[\mathrm{CoO}_{2}\right]_{1.62}$ (close to the present misfit system) contains considerable amounts of oxygen vacancies [31]. In order to evaluate the thermoelectric performance of these materials, the power factor has been calculated. The temperature and Ag dependences of PF are calculated from the resistivity and TEP data and displayed in Fig. 11. The power factor at room temperature is increased, from 0.02 to $0.10 \mathrm{~mW} / \mathrm{K}^{2} . \mathrm{m}$, when the Ag contents is increased from 0 to $5 \mathrm{wt} . \%$. This maximum value is higher by one order of magnitude when compared to those measured in randomly oriented grains ceramics (equal to $0.01 \mathrm{~mW} / \mathrm{K}^{2} . \mathrm{m}$ ), and comparable to those reported at around $550 \mathrm{~K}$ by Itahara et al. using the reactive templated grain growth (RTGG) technique and measuring on the ab plane [29].

\subsection{Electric characterization of annealed Bi-2212/Ag composites}

Fig. 12 shows the temperature dependence of the resistivity as a function of $\mathrm{Ag}$ content for annealed Bi-2212/Ag composites. In this figure, it can be seen that $T_{c}$ is the same for all the samples indicating the same intragranular behaviour in 
all cases. As a consequence it can be deduced that Ag is not incorporated in the superconductor crystalline structure. Moreover, the high temperature resistivity values are very similar for all the samples indicating good electrical grains connectivity even when Ag is not present. The slight increase on the high temperature resistivity found for the $5 \mathrm{wt}$ \%Ag samples can be probably associated to the superconducting grain misalignment around the big $\mathrm{Ag}$ particles, as observed in Fig. 6.

The evolution of the $\mathrm{J}_{\mathrm{c}}$ values as a function of the $\mathrm{Ag}$ content at $77 \mathrm{~K}$ is shown in Fig. 13. As it can be clearly seen in this figure, $\mathrm{J}_{\mathrm{c}}$ values higher than 3500 $\mathrm{A} / \mathrm{cm}^{2}$ are obtained for $\mathrm{Ag}$ added samples. The low value found for the undoped sample is due to the thermal treatment which is not the optimal one for pure Bi2212 compositions. When the undoped samples are properly treated, they reach, approximately, the same critical current values [32]. These results confirm that $\mathrm{Ag}$ addition has not a negative effect on the electrical transport properties. In fact, for the prepared samples (about $2 \mathrm{~mm}$ diameter) is possible to get electrical intensities as high as around $100 \mathrm{~A}$ without resistive loses.

\section{CONCLUSIONS}

It has been demonstrated that it is possible to obtain textured $\mathrm{Bi}-2212 / \mathrm{Ag}$ and BSCO/Ag advanced ceramic composites, through a directional growth process from the melt by the laser floating zone melting technique. This technique can be useful to obtain improved properties on materials with high anisotropic properties, as Bi-based ceramic superconductors and Co-based thermoelectric oxides. In all cases, Ag addition improves flexural strength by providing a plastic-flow region which reduces crack propagation. It has been found that for 
this layered systems, the optimal $\mathrm{Ag}$ addition is about $1 \mathrm{wt} . \% . \mathrm{Ag}$ appears as small spherical or ellipsoidal particles between the plate-like grains for the asgrown or annealed samples, respectively. Increasing Ag content leads to bigger precipitates which can produce a detrimental effect on their mechanical properties.

From the electrical point of view, it has been also shown that Ag addition improves grains connectivity in the case of the BSCO/Ag composites. In these materials a very important reduction on the resistivity values at room temperature has been obtained, from 1300 to $200 \mu \Omega$.m with additions of 3 wt.\%Ag. In the case of $\mathrm{Bi}-2212 / \mathrm{Ag}$ composites, Ag addition does not affect significantly superconducting grains connectivity.

\section{ACKNOWLEDGEMENTS}

The authors wish to thank the Spanish Ministry for Science and Innovation (MICINN-FEDER, MAT2008-00429 and MAT2008-05983-C03-01 projects) and the Gobierno de Aragón (Research Groups T12 and T72) for financial support. The technical contributions of J.A. Gómez and C. Gallego are also acknowledged.

\section{References}

[1] Bednorz J. G.; Müller K. A. Z. Phys. B-Condensed Matter 1986, 64, 189-193.

[2] Terasaki I.; Sasago Y.; Uchinokura K. Phys. Rev. B 1997, 56, 12685-12687.

[3] Maeda H.; Tanaka Y.; Fukutomi M.; Asano T. Jpn. J. Appl. Phys. Lett. 1988, 27, L209-L210. 
[4] Funahashi R.; Matsubara I.; Sodeoka S. Appl. Phys. Lett. 2000, 76, 23852387.

[5] Herrmann P. F. Current leads. In Handbook of Applied Superconductivity; Seeber, B., Ed.; IOP Publishing Ltd.: Bristol and Philadelphia, 1998; pp. 801843.

[6] Noe M.; Juengst K. P.; Werfel F. N.; Elschner S.; Bock J.; Breuer F.; Kreutz R. IEEE Trans. Appl. Supercond. 2003, 13, 1976-1979.

[7] Garnier V.; Caillard R.; Sotelo A.; Desgardin G. Physica C 1999, 319, 197208.

[8] Martin-Gonzalez M. S.; Garcia-Jaca J.; Moran E.; Alario-Franco M. A. J. Mater. Res. 1999, 14, 3497-3505.

[9] Maeda H.; Ohya K.; Sato M.; Chen W. P.; Watanabe K.; Motokawa M.;

Matsumoto A.; Kumakura H.; Schwartz J. Physica C 2002, 382, 33-37.

[10] Zhang Y. F.; Zhang J. X.; Lu Q. M. Ceram. Int. 2007, 33, 1305-1308.

[11] Seabaugh M. M.; Kerscht I. H.; Messing C. L. J. Am. Ceram. Soc. 1997, 80, $1181-1188$.

[12] Feigelson R. S.; Gazit D.; Fork D. K.; Geballe T. H. Science 1988, 240, 1642-1645.

[13] Sotelo A.; Madre M. A.; Diez J. C.; Rasekh Sh.; Angurel L. A.; Martınez E. Supercond. Sci. Technol. 2009, 22, 034012.

[14] Diez J. C.; Guilmeau E.; Madre M. A.; Marinel S.; Lemmonier S.; Sotelo A. Solid State Ionics 2009, 180, 827-830.

[15] Revcolevschi A.; Jegoudez J. Prog. Mater. Sci. 1997, 42, 321-339.

[16] Pastor J. Y.; Poza P.; Llorca J. J. Am. Ceram. Soc. 1999, 82, 3139-3144. 
[17] Joo J.; Singh J. P.; Warzynski T.; Grow A.; Poeppel R. B. Appl. Supercond. 1994, 2, 401-410.

[18] Ruiz M. T.; de la Fuente G. F.; Badía A.; Blasco J.; Castro M.; Sotelo A.;

Larrea A.; Lera F.; Rillo C.; Navarro R. J. Mater. Res. 1993, 8, 1268-1276.

[19] Sotelo A.; de la Fuente G. F.; Lera F.; Beltrán D.; Sapiña F.; Ibáñez R.;

Beltrán A.; Bermejo M. R. Chem. Mater. 1993, 5, 851-856.

[20] Carrasco M. F.; Costa F. M.; Silva R. F.; Gimeno F.; Sotelo A.; Mora M.;

Diez J. C.; Angurel L. A. Physica C 2004, 415, 163-171.

[21] Funahashi R.; Matsubara I.; Ueno K.; Ishikawa H. Physica C 1999, 311, 107-121.

[22] Mora M.; Martinez E.; Diez J. C.; Angurel L. A.; de la Fuente G. F. J. Mater. Res. 2000, 15, 614-620.

[23] Sotelo A.; Guilmeau E.; Madre M. A.; Marinel S.; Lemmonier S.; Diez J. C.

Bol. Soc. Esp. Ceram. V. 2008, 47, 225-228.

[24] de la Fuente G. F.; Diez J. C.; Angurel L. A.; Peña J. I.; Sotelo A.; Navarro R. Adv. Mater. 1995, 7, 853-856.

[25] Klein Y.; Pelloquin D.; Hebert S.; Maignan A.; Hejtmanek J. J. Appl. Phys. 2005, 98, 013701.

[26] Xu G. J.; Funahashi R.; Shikano M.; Matsubara I.; Zhou Y. Q. J. Appl.

Phys. 2002, 91, 4344-4347.

[27] Majewski P.; Sotelo A.; Szillat H.; Kaesche S.; Aldinger F. Physica C 1997, $275,47-51$.

[28] Kasap S. O. Principles of electronic materials and devices; McGraw-Hill: New York, 2006.

[29] Itahara H.; Xia C.; Sugiyama J.; Tani T. J. Mater. Chem. 2004, 14, 61-66. 
[30] Maignan A.; Pelloquin D.; Hebert S.; Klein Y.; Hervieu M. Bol. Soc. Esp.

Ceram. V. 2006, 45, 122-125.

[31] Karppinen M.; Fjellvag H.; Konno T.; Morita Y.; Motohashi T.; Yamauchi H.

Chem. Mater. 2004, 16, 2790-2793.

[32] Angurel L. A.; Diez J. C.; Martinez E.; Peña J. I.; de la Fuente G. F.;

Navarro R. Physica C 1998, 302, 39-50. 


\section{Figure captions}

Figure 1. SEM micrographs performed on longitudinal polished sections of the as-grown materials. (a) Bi-2212/3 wt.\%Ag, and (b) BSCO/5 wt.\%Ag. The different phases are: 1) (Ca,Sr) $\left.\left.\mathrm{CuO}_{2}, 2\right) \mathrm{Bi}-2201,3\right) \mathrm{Bi}-2212 / \mathrm{Bi}-2201$ intergrowths, 4) $\left.\mathrm{CaO}, 5) \mathrm{Ag}, 6) \mathrm{Bi}_{2} \mathrm{Sr}_{2} \mathrm{Co}_{2} \mathrm{O}_{y}, 7\right) \mathrm{Bi}_{2} \mathrm{Sr}_{2} \mathrm{CoO}_{y}$, 8) Co-free, 9) $\mathrm{CoO}$, and 10) $\mathrm{Sr}_{2} \mathrm{Co}_{2.8-\mathrm{x}} \mathrm{Bi}_{x} \mathrm{O}_{y}$.

Figure 2. SEM micrograph performed on transversal polished section of an asgrown $\mathrm{BSCO} / 5 \mathrm{wt} . \% \mathrm{Ag}$ sample showing a big Ag particle formed in the solidification process.

Figure 3. Powder XRD plots of the as-grown BSCO/Ag composites with a) 0 ; b) 1; c) 3; and d) 5 wt.\%Ag. $\nabla$ Bi-Sr-O secondary phases; $\downarrow$ Si used as reference; and \# Ag.

Figure 4. Powder XRD plots of the annealed Bi-2212/Ag composites with a) 0;

b) 1; c) 3; and d) 5 wt.\%Ag. * Bi-2201 secondary phases; and \# Ag.

Figure 5. SEM micrograph performed on transversal polished section of the annealed Bi-2212/3 wt.\%Ag showing the different phases, grey contrast corresponds to $\mathrm{Bi}-2212$, white contrast to $\mathrm{Bi}-2201$, and dark grey to $(\mathrm{Sr}, \mathrm{Ca}) \mathrm{CuO}_{2}$. Ag particles are indicated by arrows.

Figure 6. SEM micrograph performed on transversal polished section of the annealed $\mathrm{Bi}-2212 / 5 \mathrm{wt} . \% \mathrm{Ag}$ showing a big Ag particle which does not change its shape during the annealing process.

Figure 7. Flexural strength for the as-grown BSCO/Ag samples as a function of the Ag content. The error bars indicate the obtained standard error.

Figure 8. Flexural strength for the annealed $\mathrm{Bi}-2212 / \mathrm{Ag}$ samples as a function of the Ag content. The error bars indicate the obtained standard error. 
Figure 9. Temperature dependence of the electrical resistivity as a function of the Ag content in as-grown BSCO/x wt.\%Ag samples, for $\mathrm{x}=0(\bullet)$; $1(\bullet) ; 3(\bullet)$; and $5(\mathbf{\Delta})$.

Figure 10. Temperature dependence of the thermopower as a function of the Ag content in as-grown BSCO/x wt.\%Ag samples, for $\mathrm{x}=0(\bullet)$; $1(\bullet)$; $3(\mathbf{\square})$; and $5(\mathbf{\Delta})$.

Figure 11. Temperature dependence of the power factor as a function of the $\mathrm{Ag}$ content in as-grown BSCO/x wt.\%Ag samples, for $\mathrm{x}=0(\bullet) ; 1(\bullet) ; 3(\bullet)$; and 5

\section{$(\mathbf{\Delta})$.}

Figure 12. Temperature dependence of the electrical resistivity as a function of the Ag content in annealed Bi-2212/x wt.\%Ag samples, for $\mathrm{x}=0(\bullet)$; $1(\bullet) ; 3$ $(\mathbf{\square})$; and $5(\mathbf{\Lambda})$.

Figure 13. Critical current density values at $77 \mathrm{~K}$ as a function of the $\mathrm{Ag}$ content in annealed $\mathrm{Bi}-2212 / \mathrm{x}$ wt.\%Ag samples 
Figure 1

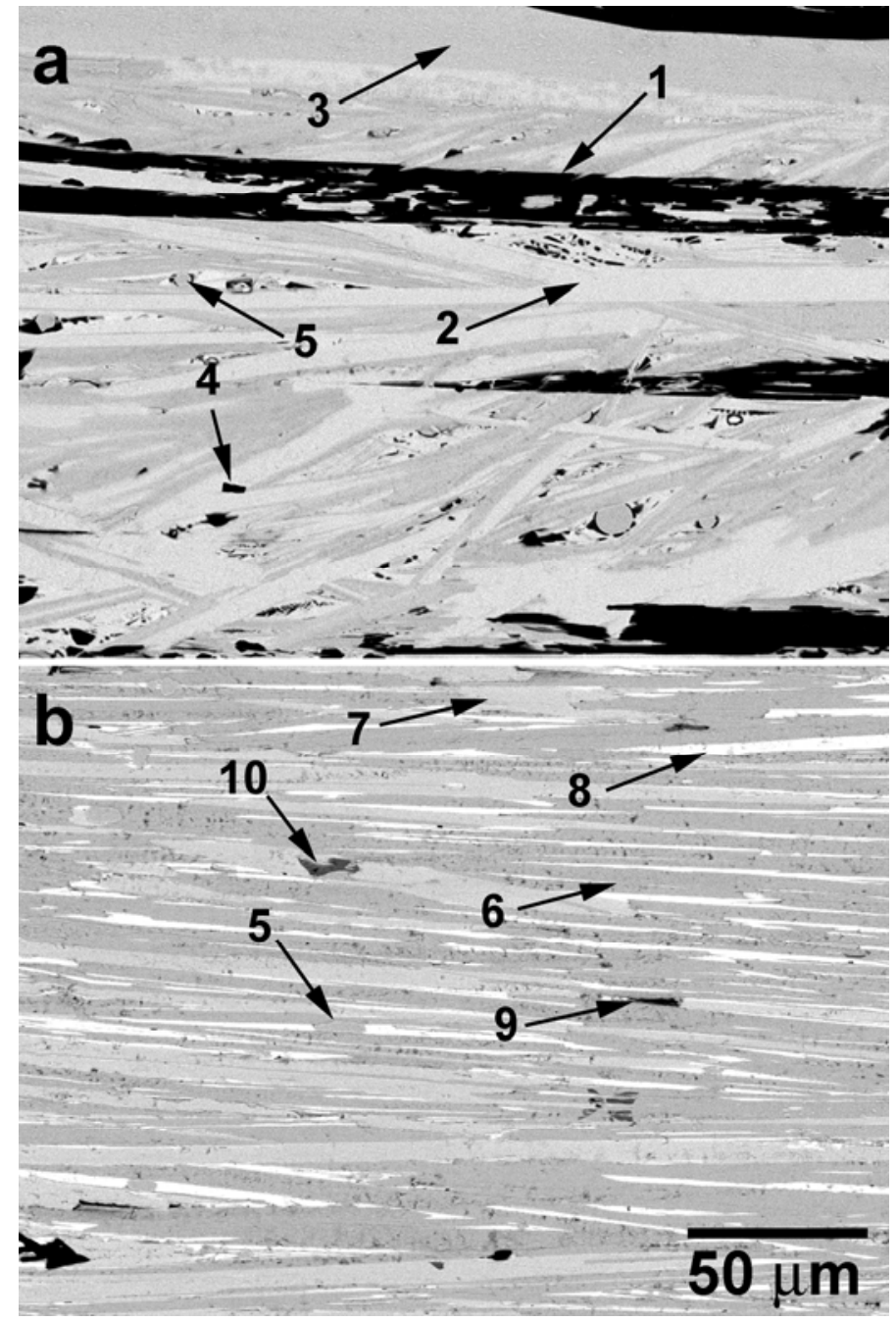


Figure 2

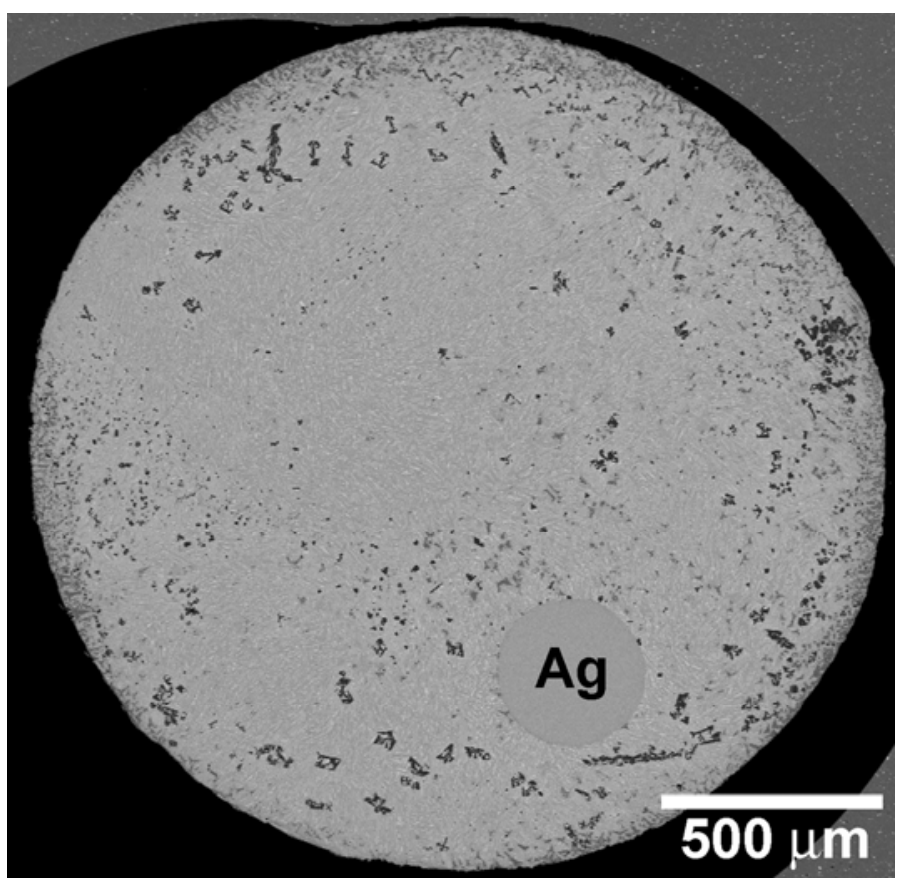


Figure 3

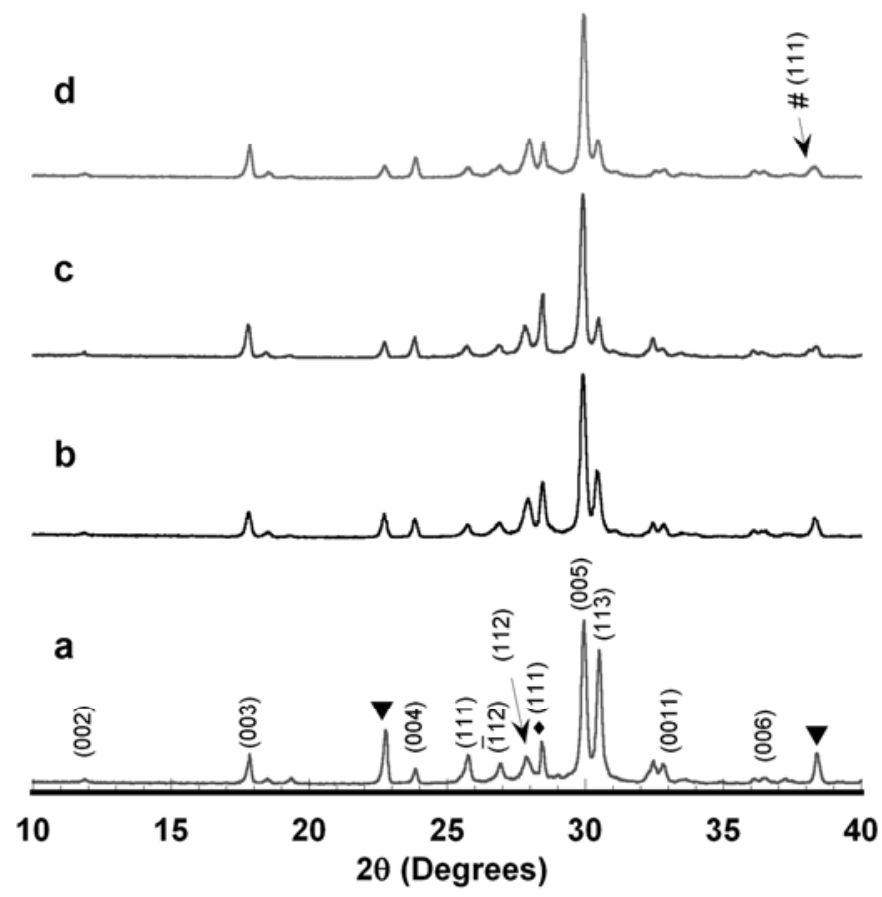


Figure 4

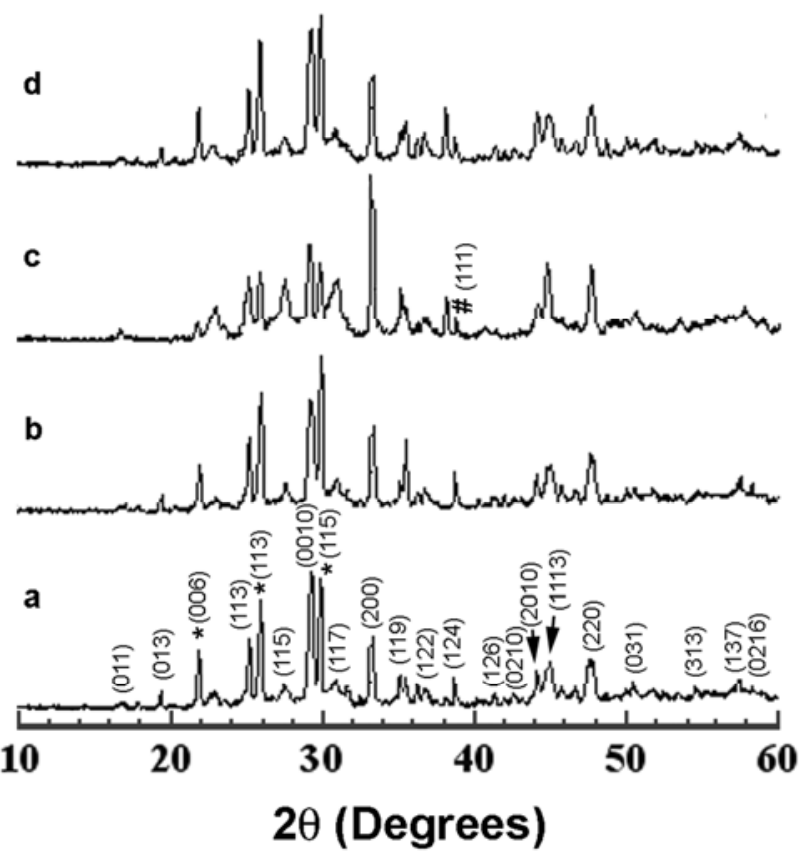


Figure 5

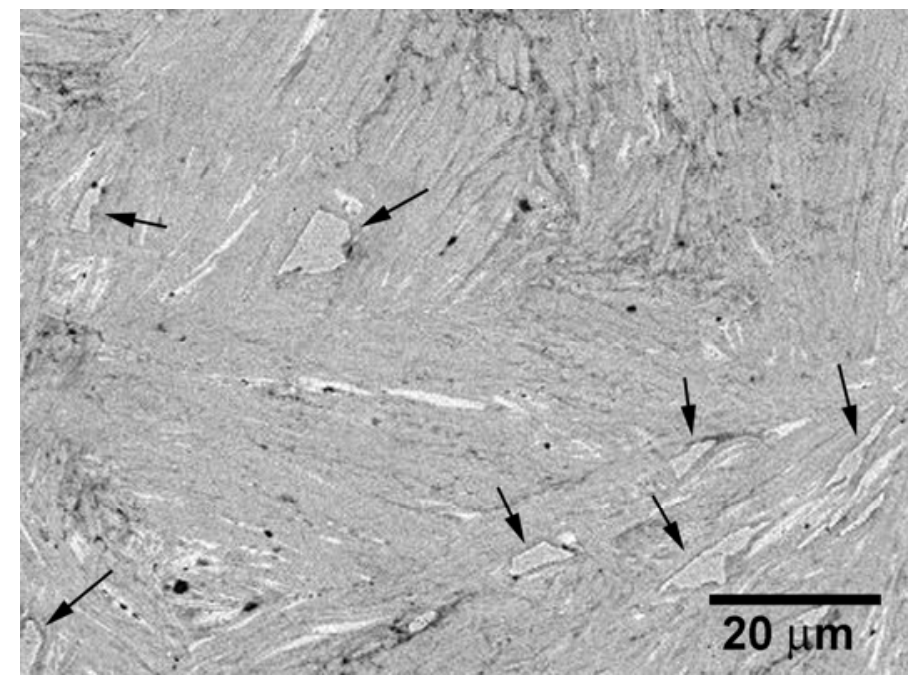


Figure 6

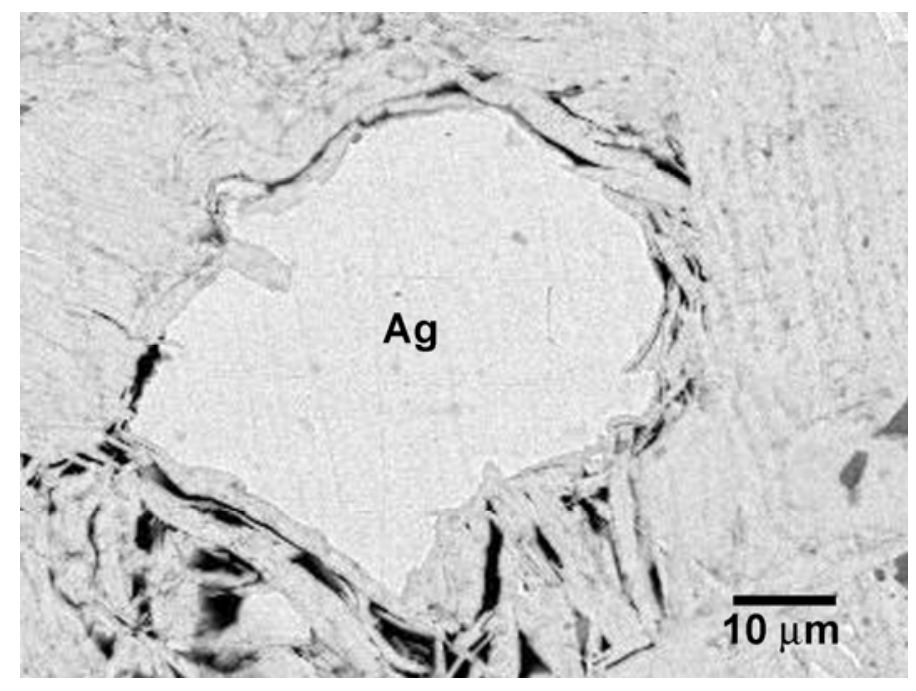


Figure 7

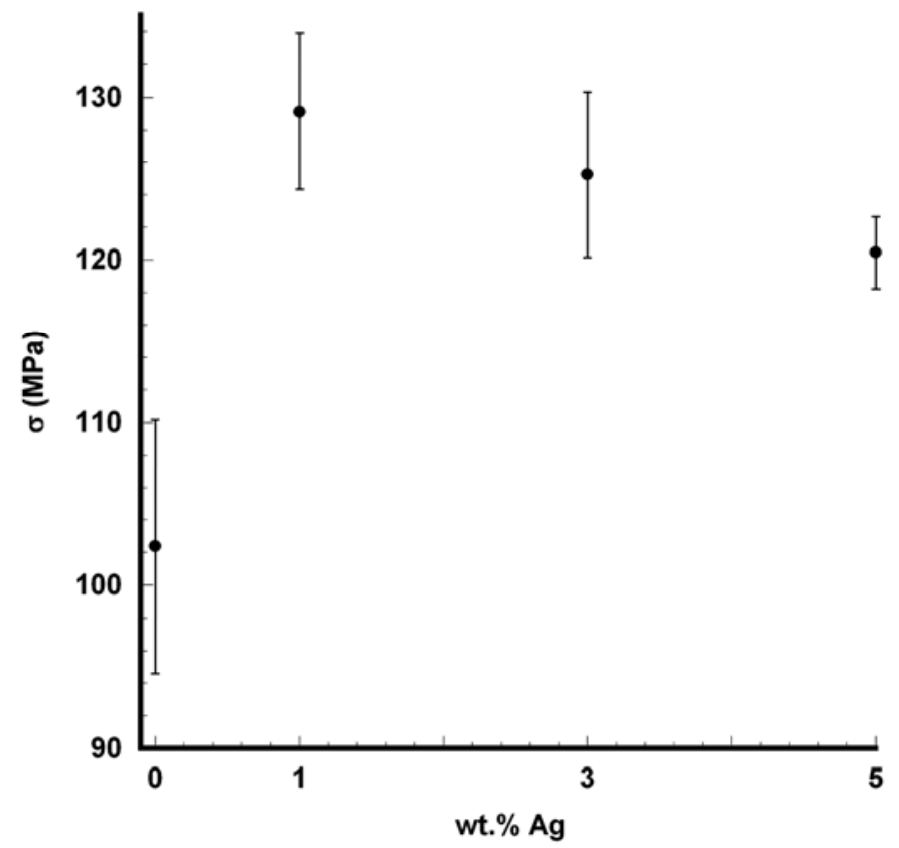


Figure 8

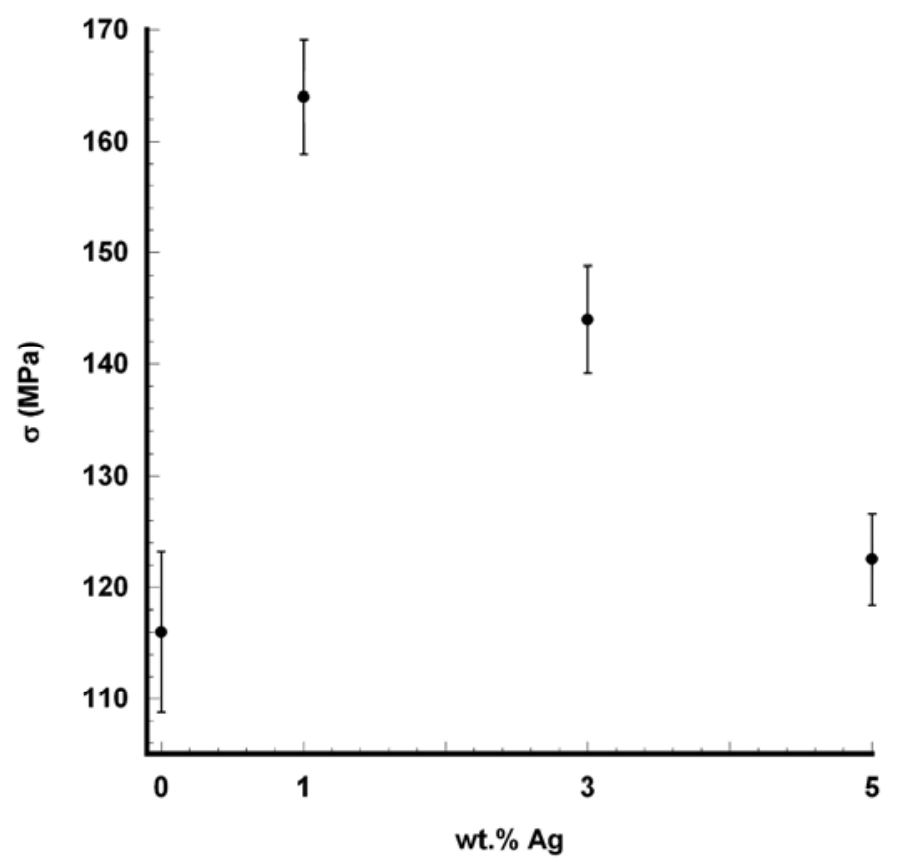


Figure 9

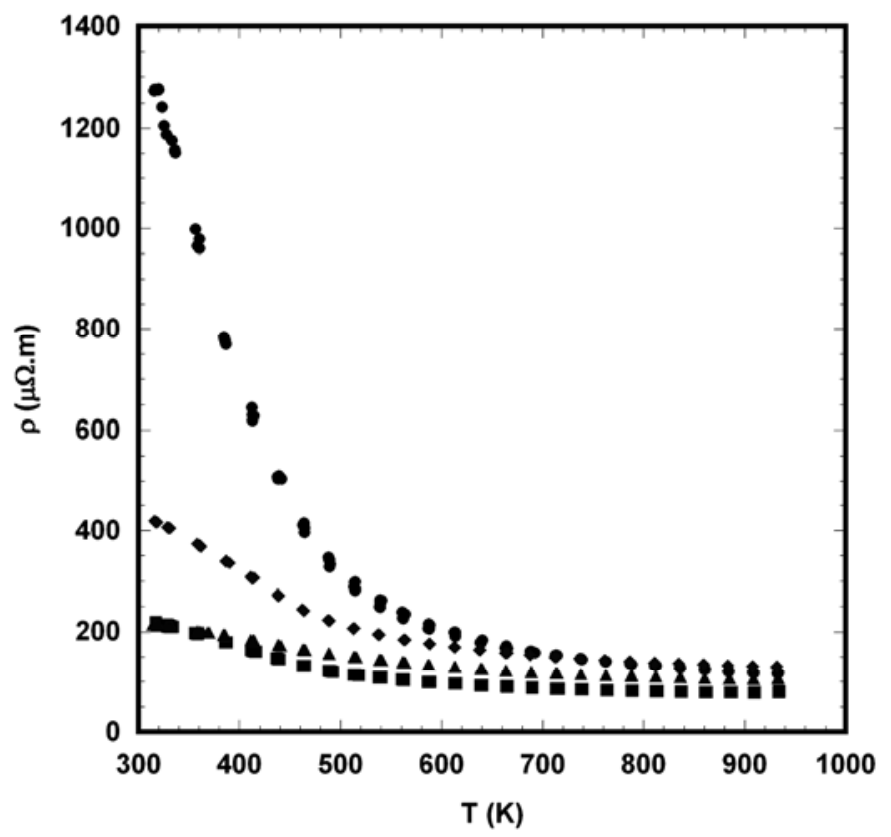


Figure 10

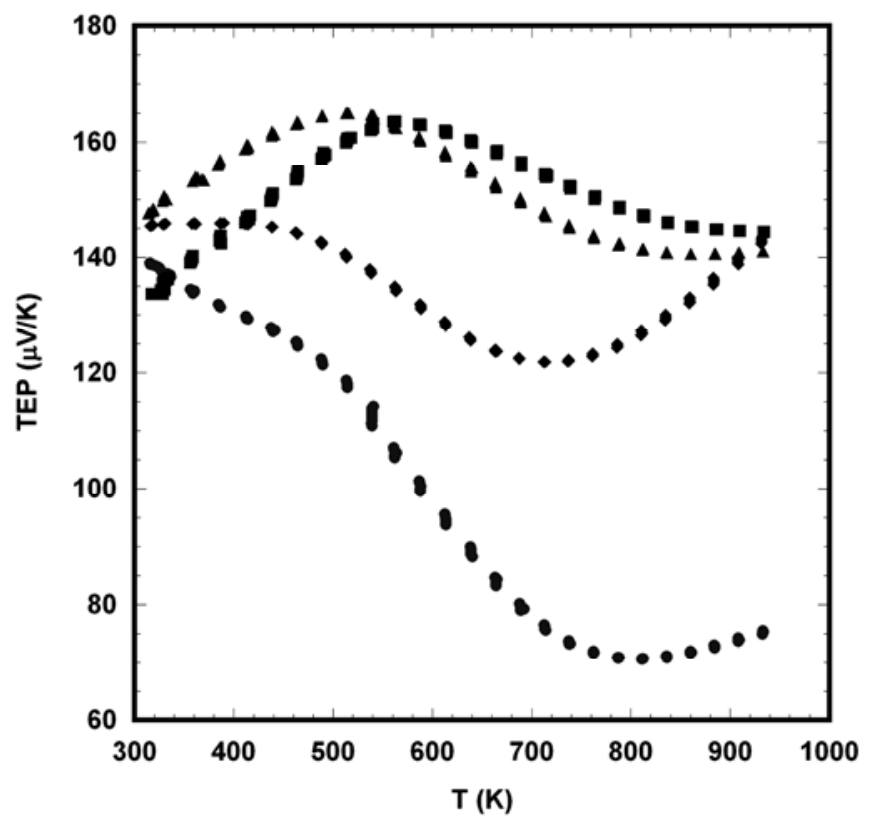


Figure 11

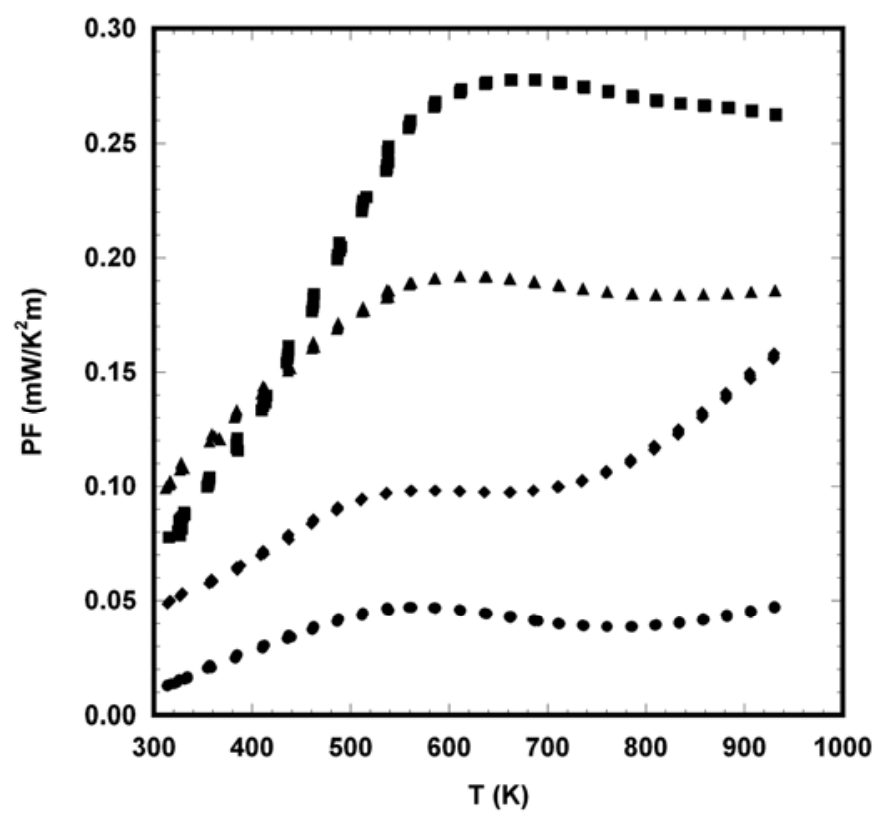


Figure 12

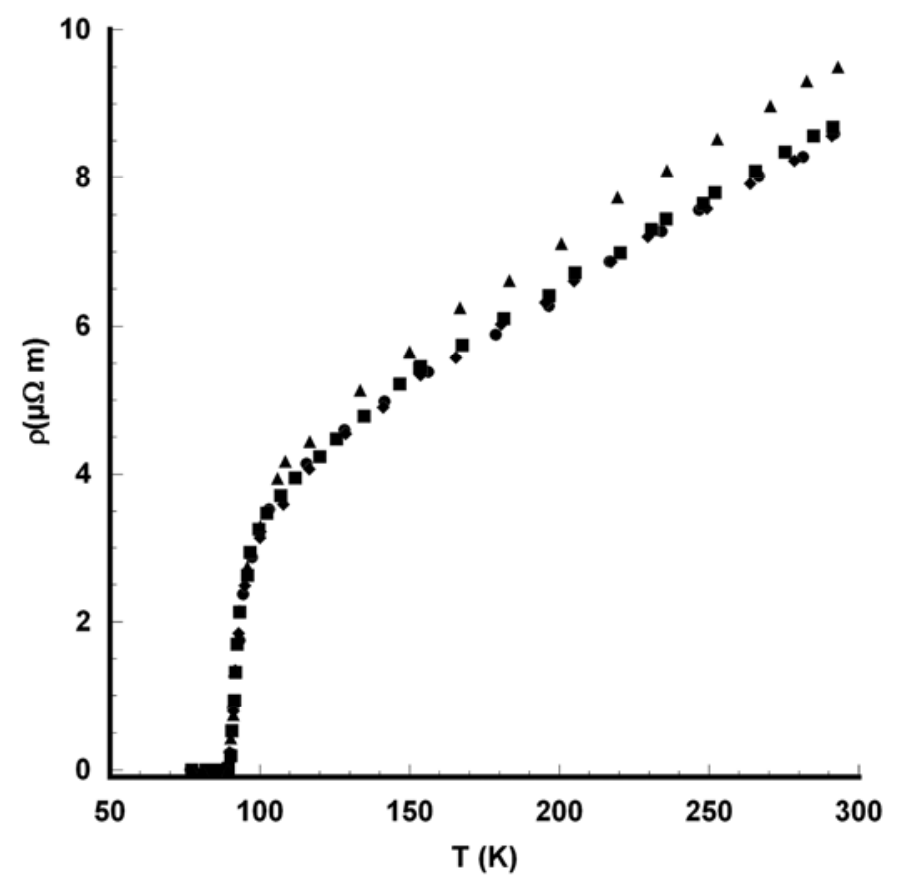


Figure 13

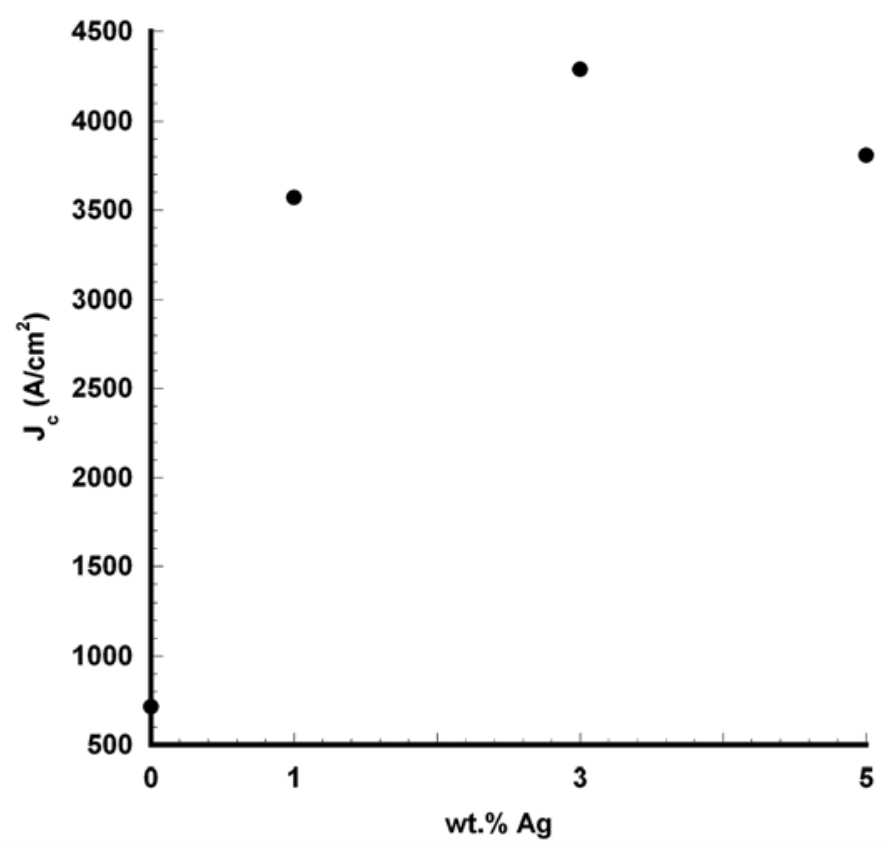

